\title{
Trends in the use of oral anticoagulants, antiplatelets and statins in four European countries: a population-based study
}

\author{
Luis A. García Rodríguez ${ }^{1}$ - - Lucía Cea Soriano ${ }^{2}$. Francisco J. de Abajo ${ }^{3}$. Francesca Valent ${ }^{4}$. Jesper Hallas ${ }^{5}$. \\ Miguel Gil $^{6}$. Chiara Cattaruzzi ${ }^{7}$. Sara Rodriguez-Martin ${ }^{3} \cdot{\text { Pareen } \text { Vora }^{8} \cdot \text { Montse Soriano-Gabarró }^{8} \text {. David Gaist }}^{9}$
}

Received: 2 July 2021 / Accepted: 7 November 2021 / Published online: 17 November 2021

(c) The Author(s) 2021

\begin{abstract}
Purpose To evaluate time trends in the prevalence of antithrombotic and statin use in four European countries.

Methods Using population-based data from the United Kingdom, Denmark, Spain and Italy between 2010 and 2018, we calculated standardized annual prevalence proportions of antithrombotics and statin use, and changes in prevalence proportions (2018 vs. 2010).

Results Prevalence proportion of statins increased from 24.8\% to 24.6\% (UK), 21.0\% to 22.3\% (Region of Southern Denmark [RSD]), $12.9 \%$ to $14.3 \%$ (Udine, Italy), and $20.3 \%$ to $23.2 \%$ (Spain). Prevalence proportions of antithrombotics declined in all four countries: $18.7 \%$ to $15.9 \%$ (UK; $-2.8 \%$ points), $18.9 \%$ to $18.1 \%$ (RSD; $-0.8 \%$ points), $17.7 \%$ to $16.6 \%$ (Udine; $-1.1 \%$ points) and $15.0 \%$ to $13.6 \%$ (Spain; $-1.4 \%$ points). These declines were driven by reductions in low-dose aspirin use: $15.3 \%$ to $8.9 \%$ (UK; $-6.4 \%$ points), $16.3 \%$ to $9.5 \%$ (RSD; $-6.8 \%$ points), $13.5 \%$ to $11.6 \%$ (Udine; $-1.9 \%$ points), and $10.2 \%$ to $8.8 \%$ (Spain; $-1.4 \%$ points). In the UK, low-dose aspirin use declined from $9.1 \%$ to $4.3 \%$ ( $-4.8 \%$ points) for primary CVD prevention, and from $49.6 \%$ to $36.9 \%$ ( $-12.7 \%$ points) for secondary prevention. Oral anticoagulant use gradually increased but did not fully account for the decrease in low-dose aspirin use.

Conclusions Antithrombotic use in the UK, RSD, Udine and Spain declined between 2010 and 2018, driven by a reduction in use of low-dose aspirin that is not completely explained by a gradual increase in OAC use. Use of statins remained constant in the UK, and increased gradually in the RSD, Udine and Spain.
\end{abstract}

Keywords Antithrombotics $\cdot$ Aspirin $\cdot$ Anticoagulants $\cdot$ Statins $\cdot$ Database $\cdot$ Trends

Luis A. García Rodríguez

lagarcia@ceife.es

1 Spanish Centre for Pharmacoepidemiologic Research (CEIFE), Madrid, Spain

2 Department of Public Health and Maternal and Child Health, Faculty of Medicine, Complutense University of Madrid), Madrid, Spain

3 Clinical Pharmacology Unit, Department of Biomedical Sciences (Pharmacology Section), University Hospital Príncipe de Asturias, University of Alcalá (IRYCIS), Alcalá de Henares, Madrid, Spain

4 Institute of Hygiene and Clinical Epidemiology, Udine Integrated University Health Unit, Udine, Italy
5 Clinical Pharmacology and Pharmacy, Department of Public Health, University of Southern Denmark, Odense, Denmark

6 División de Farmacoepidemiología Y Farmacovigilancia, Agencia Española de Medicamentos Y Productos Sanitarios, Madrid, Spain

7 Pharmaceutical Service, Udine Integrated University Health Unit, Udine, Italy

8 Bayer AG, Berlin, Germany

9 Research Unit for Neurology, Odense University Hospital, University of Southern Denmark, Odense, Denmark 


\section{Introduction}

Despite a decline in cardiovascular disease (CVD) mortality, CVD including ischaemic heart disease and stroke, remains the leading cause of death in Europe, accounting for approximately $45 \%$ of all deaths [1]. The burden of CVD - both direct and indirect costs - similarly remains high $[1,2]$. While lifestyle changes, antithrombotic therapy, statins as lipid-lowering therapy, and antihypertensives remain the cornerstone of CVD prevention, the last decade has seen the introduction of the direct oral anticoagulants (DOACs) as a new class of oral anticoagulants (OACs) along with changes to CVD prevention guidelines. For example, the 2010 European Society of Cardiology (ESC) guidelines no longer recommended use of low-dose aspirin for thromboprophylaxis in patients with atrial fibrillation (AF) [3], while the recent 2019 ESC guidelines for the management of dyslipidaemia indicate the potential for statin use in broader patient populations [4]. Furthermore, while antiplatelet therapy with low-dose aspirin remains recommended for secondary prevention of CVD [5, 6], its use in primary CVD prevention is largely not recommended. European Society of Cardiology (ESC) guidelines continue to advise against prescribing low-dose aspirin for primary prevention [6,7], yet some position statements have advocated a more nuanced approach and focus mainly on patients with high CVD and low-bleeding risks $[8,9]$.

Owing to these changes in CVD management strategies, it is important to monitor how these commonly used CVD drugs are being prescribed at the population-level; however, large population-based studies evaluating countrylevel trends in prescriptions rates are limited. In this study, we used population-based clinical data from four European countries to describe time-trends in the use of antithrombotics and statins over a contemporary 9-year period. Our main interest was in the use of antiplatelets (and particularly low-dose aspirin) as we hypothesised that we would observe a decline in their use over time due to the changes in guidelines. Anticoagulants and statins were selected for this study as examples of two other commonly used CVD therapies, in order to see whether similar or different trends were seen in their use as with antiplatelets.

\section{Methods}

\section{Data sources}

The study used patient-level data from four European countries that all have national healthcare systems - the United Kingdom (UK), Denmark, Italy and Spain - using longitudinal healthcare databases that are considered representative of the general population/region for that country: the IQVIA Medical Research Data (IMRD) database, linked registries covering the Region of Southern Denmark (RSD), the Friuli Venezia Giulia database of the Udine Integrated University Health Unit in Italy (FVG ASUIUD) and Base de Datos para la Investigación Farmacoepidemiológica en Atención Primaria (BIFAP) primary care database in Spain (see the Supplementary Methods for further details on the data sources). These data sources were chosen based on the principal investigator in each location being willing and having access to the data for the respective analyses.

\section{Patient and public involvement}

There was no public or patient involvement in the design, conduct, reporting or dissemination plans of our research.

\section{Study population}

The study population from each data source included individuals aged between 40 and 99 years of age for each calendar year within the 9-year study period from 1 January 2010 to 31 December 2018. This time period was chosen to enable analysis of the most recent available data from each data source while also providing a long enough period to identify any contemporary time trends. For the UK and Spanish analyses, only individuals with a permanent registration status with the primary care physician were included.

\section{Antithrombotics and statins}

For each country-specific study population, we identified all prescriptions for antithrombotics (antiplatelets and OACs) and statins during the study period (see Supplementary Table 1 for codes). Antiplatelets were categorized as lowdose aspirin (75-325 mg tablets in the UK, 75-150 mg tablets in Denmark, 75-300 mg tablets in Italy, and 75 to $300 \mathrm{mg}$ tablets in Spain), clopidogrel, or 'other' (ticagrelor, prasugrel, and triflusal). Oral anticoagulants included all vitamin $\mathrm{K}$ antagonists (VKAs) and DOACs available during the study period. To qualify as a user of one of these drug classes in a specific calendar year, individuals were required to have at least one prescription for the drug in that year.

\section{Statistical analysis}

Annual prevalence proportions of use of each drug class were expressed as a percentage and were calculated by dividing the number of individuals with a prescription for the drug class in question in each calendar year by the number of individuals alive in the respective database on the 
1 January of that calendar year. To enable valid comparisons between countries and between calendar years in each database, direct age- and sex-standardization was performed using the age (10-year age bands) and sex distribution from the Eurostat reference population [10]. For low-dose aspirin use, annual prevalence proportions were also stratified by age and sex. We calculated the percentage change - both absolute difference and relative difference - in prevalence proportion of each drug class over the study period. Relative differences in annual prevalence proportions was calculated by dividing the difference in prevalence between 2018 and 2010 by the prevalence in 2010 and multiplying by 100 . In a post-hoc analysis of the data from the UK and Spain, we calculated annual prevalence proportions, and absolute percentage change in use (2018 vs. 2010) of low-dose aspirin according to whether it was prescribed for primary or secondary CVD prevention (see Supplementary Methods for details). We were unable to perform this post-hoc analysis for the RSD and Udine because we did not have data on the indication for low-dose aspirin use at our disposal in the datasets for these two countries. To do this, for each calendar year we considered individuals with a code for CVD any time before 1 January of that calendar year as having received low-dose aspirin for secondary CVD prevention; all remaining individuals were assumed to have received it for primary CVD prevention. Additionally, among the secondary CVD prevention population in the UK, we analysed prevalence rates by aspirin indication, e.g. stroke,

A: UK
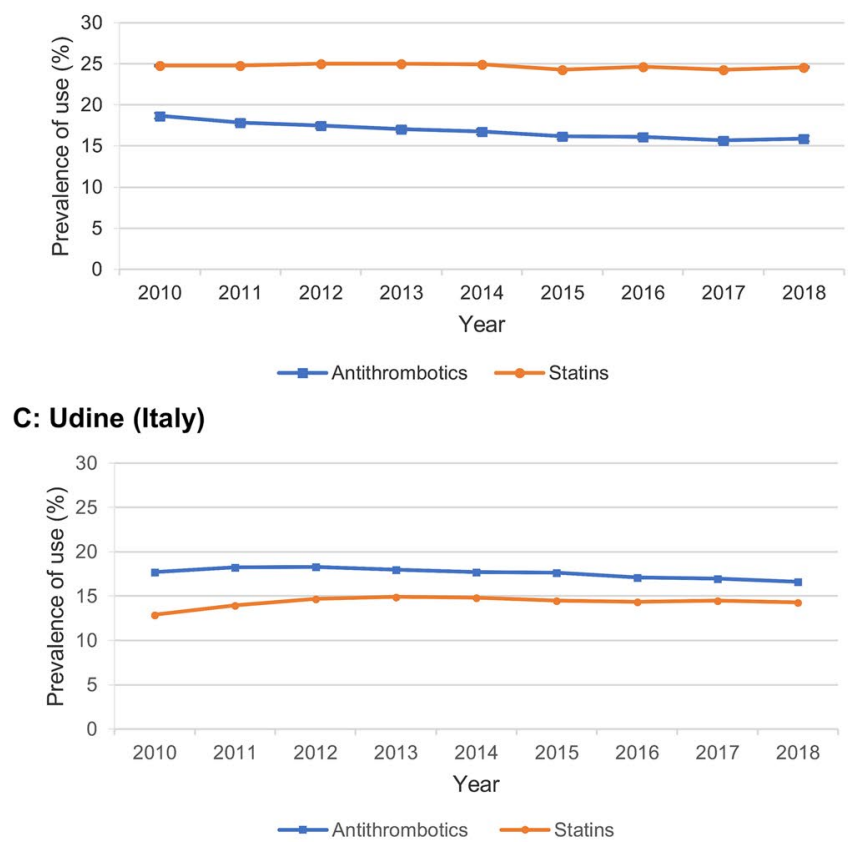

myocardial infarction, ischaemic heart disease etc.) using the closest recorded CVD code before the first low-dose aspirin prescription in each calendar year to determine the indication. Analyses were undertaken using Stata version 12.0 (StataCorp. 2017).

\section{Results}

\section{Statins and all antithrombotics}

Over the study period, the use of statins remained broadly consistent in the UK $(24.8 \%$ in 2010 and $24.6 \%$ in 2018 , dipping slightly from 2015-2018) and increased slightly in the RSD (21.0\% to $22.3 \%$ ), Udine (12.9\% to $14.3 \%$ ) and Spain (20.3\% to $23.2 \%$ ) (Fig. 1). Statin use was consistently higher than antithrombotic use in the UK, RSD and Spain, and consistently lower in Udine. A trend over time was seen in a reduction in use of antithrombotics in all four countries, but most notably in the UK, dropping to a lower level than the other three countries by 2018 : decreases were $18.7 \%$ to $15.9 \%$ (UK; $-2.8 \%$ points), $18.9 \%$ to $18.1 \%$ (RSD; $-0.8 \%$ points), $17.7 \%$ to $16.6 \%$ (Udine; $-1.1 \%$ points) and $15.0 \%$ to $13.6 \%$ (Spain; $-1.4 \%$ points) (Fig. 1). The declines in antithrombotic use across the study period were driven by a decrease in use of antiplatelets; decreases were $16.2 \%$ to $11.6 \%$ (UK; $-4.6 \%$ points), $17.0 \%$ to $13.3 \%$ (RSD; $-3.7 \%$ points), $14.8 \%$ to $12.8 \%$ (Udine; $-2.0 \%$ points) and $12.2 \%$

\section{B: RSD (Denmark)}
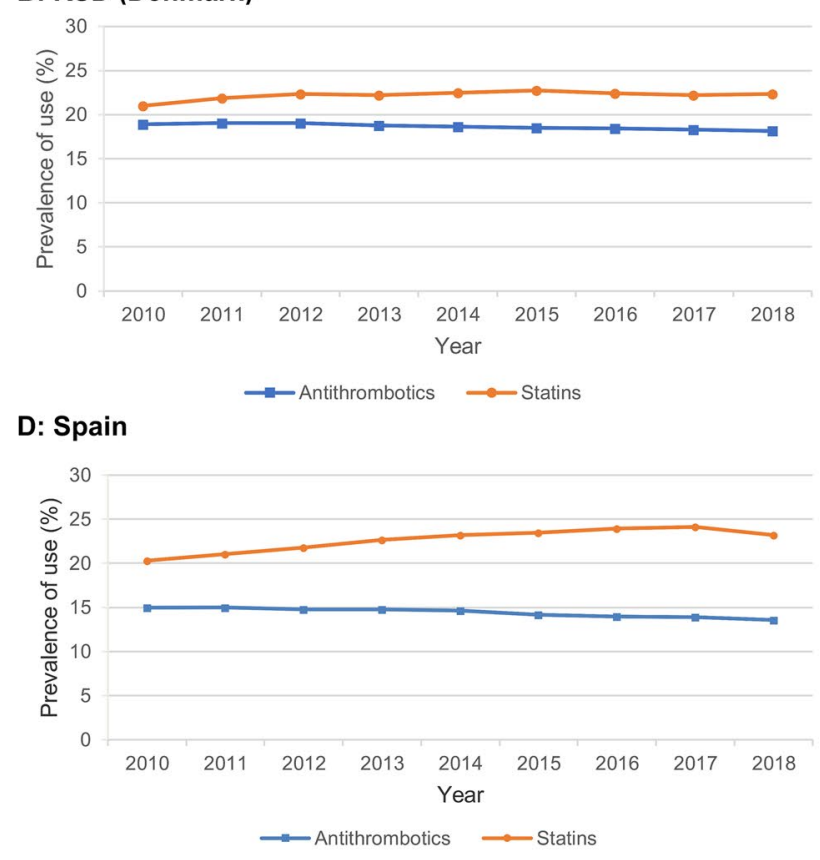

Fig.1 Annual prevalence proportion of antithrombotics and statins in A UK, B RSD (Denmark), C Udine (Italy), D Spain RSD, Region of Southern Denmark, UK, United Kingdom 

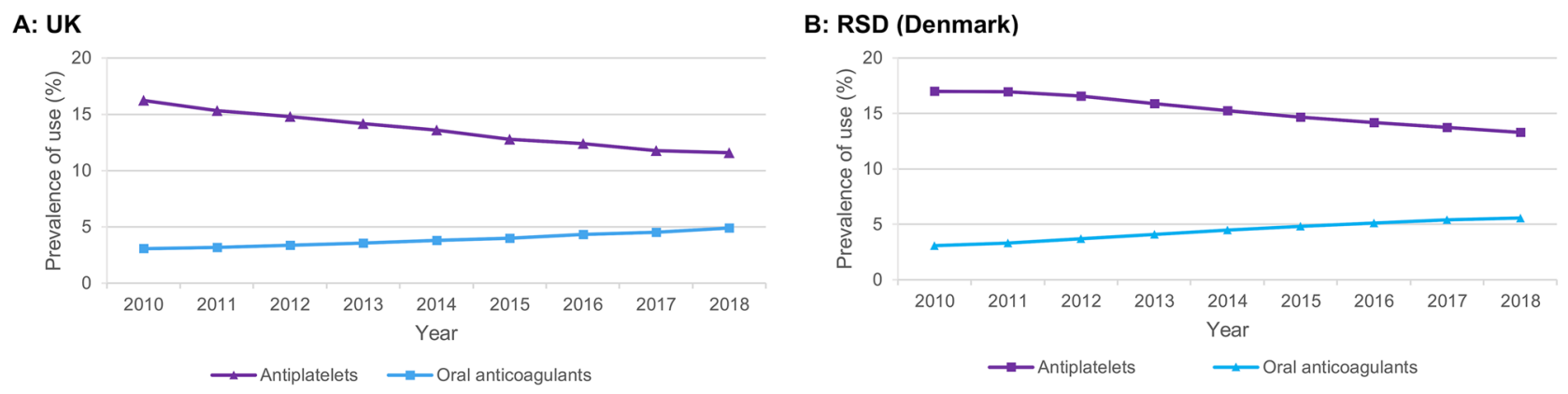

C: Udine (Italy)

D: Spain
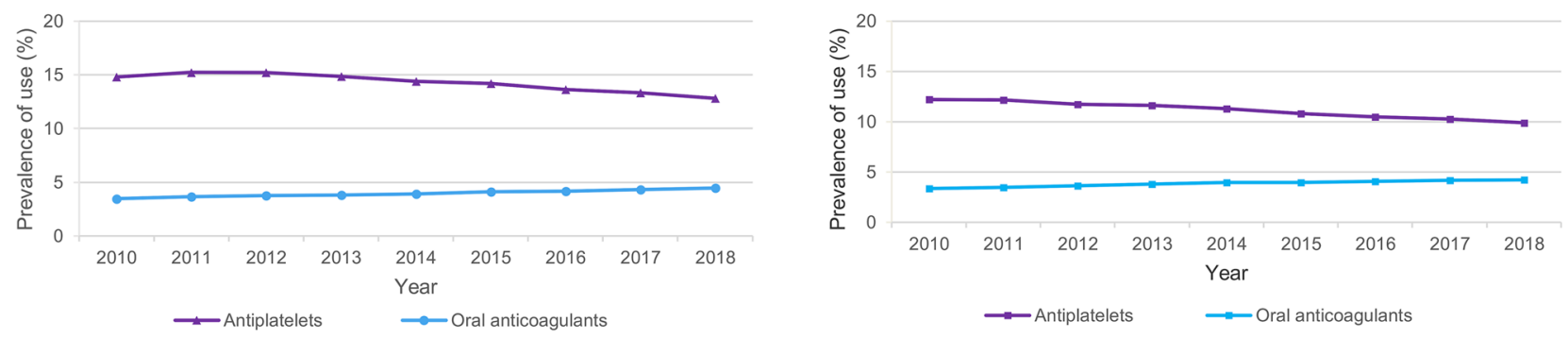

Fig. 2 Annual prevalence proportion of antiplatelets and oral anticoagulants in A UK, B RSD (Denmark), C Udine (Italy), D Spain RSD, Region of Southern Denmark, UK, United Kingdom

to $9.9 \%$ (Spain; $-2.3 \%$ points) (Fig. 2). In contrast, OAC use steadily increased in all four countries: $3.1 \%$ to $4.9 \%$ (UK; $+1.8 \%$ points), $3.1 \%$ to $5.6 \%$ (RSD $+2.5 \%$ points), $3.5 \%$ to $4.5 \%$ (Udine; $+1.0 \%$ points) and $3.4 \%$ to $4.2 \%$ (Spain; $+0.8 \%$ points) (Fig. 2). The relative change (2018 vs. 2010) in prevalence proportions antiplatelets, OACs, and statins is shown in Supplementary Fig. 1 and Supplementary Table 2; the prevalence proportion of each class of drugs in the last year of the study period (2018) is shown in Supplementary Fig. 2.

\section{Oral anticoagulants}

The increases in OAC use across the study period were driven by an increased uptake of DOACs, corresponding with decreases in VKA use (Fig. 3); use of DOACs had overtaken VKAs by 2017 in the UK and RSD, and by 2018 in Udine. VKAs remained the main OAC of use in Spain across study years.

\section{Antiplatelets}

The observed declines in antiplatelet use were driven by a decrease in low-dose aspirin use: $15.3 \%$ to $8.9 \%$ (UK; $-6.4 \%$ points), $16.3 \%$ to $9.5 \%$ (RSD; $-6.8 \%$ points), $13.5 \%$ to $11.6 \%$ (Udine; $-1.9 \%$ points), and $10.2 \%$ to $8.8 \%$ (Spain; $-1.4 \%$ points), and this was apparent in both males and females (Supplementary Fig. 3). In the UK and $\mathrm{RSD}$, greater reductions in low-dose aspirin use were seen with increasing age; however, age group differences were minimal in Udine and Spain (Supplementary Fig. 4). Use of clopidogrel increased in the UK $(1.7 \%$ to $3.4 \% ;+1.7 \%$ points), $\operatorname{RSD}(1.6 \%$ to $4.6 \% ;+3.0 \%$ points) and Udine $(0.6 \%$ to $1.6 \% ;+1.0 \%$ points), and decreased slightly in Spain ( $2.2 \%$ to $1.3 \%$; $-0.9 \%$ points) (Fig. 4$)$. The relative change (2018 vs. 2010) in the prevalence proportion of different antiplatelets is shown in Supplementary Fig. 5.

\section{Primary and secondary CVD prevention}

In the post-hoc analysis, using data from the UK and Spain, low-dose aspirin use for primary CVD prevention declined from $9.1 \%$ to $4.3 \%$ ( $-4.8 \%$ points) in the UK and from $6.7 \%$ to $5.5 \%$ (-1.2\% points) in Spain (Supplementary Fig. 6). Use of low-dose aspirin for secondary CVD prevention declined in the UK $(49.6 \%$ to $36.9 \%$; $-12.7 \%$ points) and increased very slightly in Spain $(46.6 \%$ to $47.1 \% ;+0.5 \%$ points). (Supplementary Fig. 7). Use of clopidogrel for secondary CVD prevention use increased in the UK $(8.7 \%$ to $17.5 \% ;+8.8 \%$ points $)$ and decreased in Spain (17.8\% to $10.0 \%$; $-7.8 \%$ points) (Supplementary Fig. 7).The decline in use of low-dose aspirin for secondary CVD prevention in the UK was driven by a reduction in prescribing to patients with a record of stroke $(65.1 \%$ points to $24.4 \%$ points; $-40.7 \%$ points); for patients with a record of $\mathrm{MI} /$ unstable angina/coronary revascularisation, prevalence of low-dose aspirin use declined from $77.5 \%$ to 


\section{A: UK}

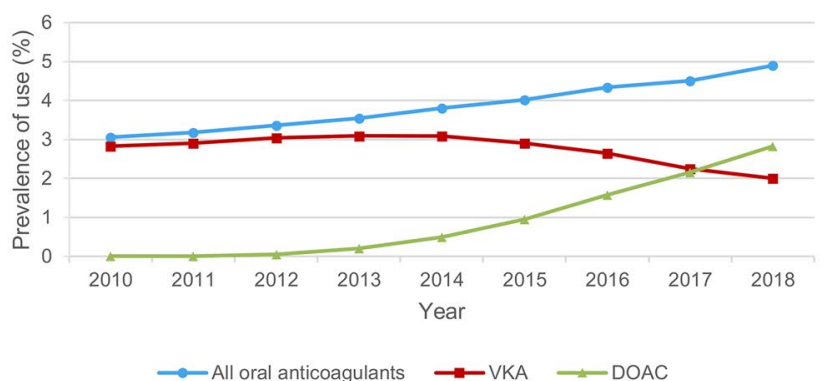

\section{C: Udine (Italy)}

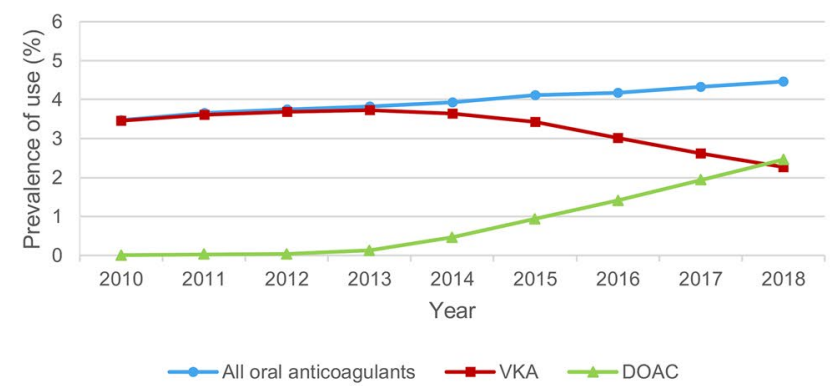

\section{B: RSD (Denmark)}

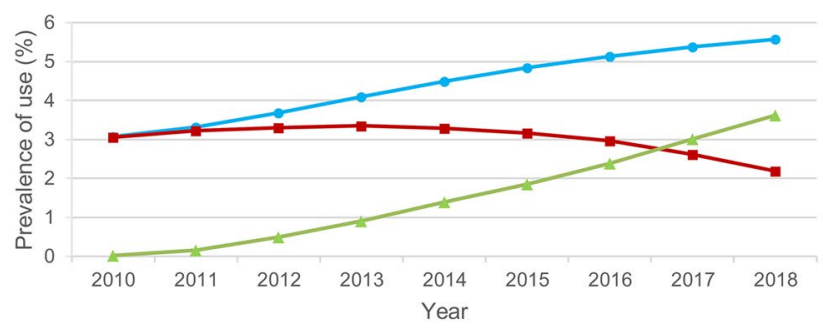

$\longrightarrow$ All oral anticoagulants $\rightarrow$ VKA $\longrightarrow$ DOAC

\section{D: Spain}

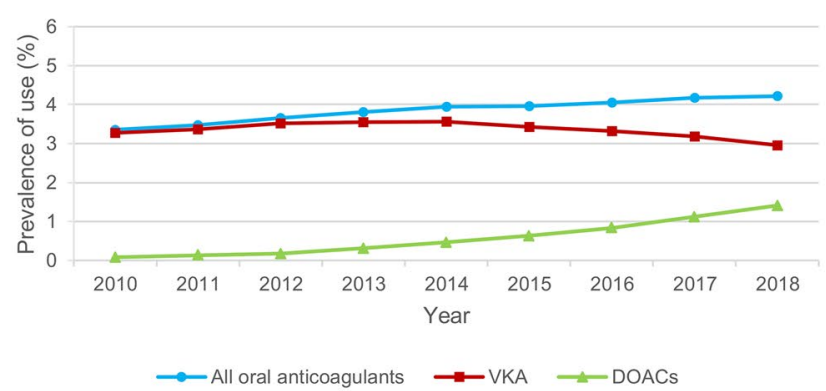

Fig. 3 Annual prevalence proportion of oral anticoagulants in A UK, B RSD (Denmark), C Udine (Italy), D Spain RSD, Region of Southern Denmark, UK, United Kingdom

$69.0 \%$ (-8.5\% points). The relative change (2018 vs. 2010) in the prevalence proportion of low-dose aspirin for primary CVD prevention was $-53.5 \%$ in the UK and $-20.1 \%$ in Spain; for secondary CVD prevention it was $-25.6 \%$ in the UK and $+1.1 \%$ in Spain.

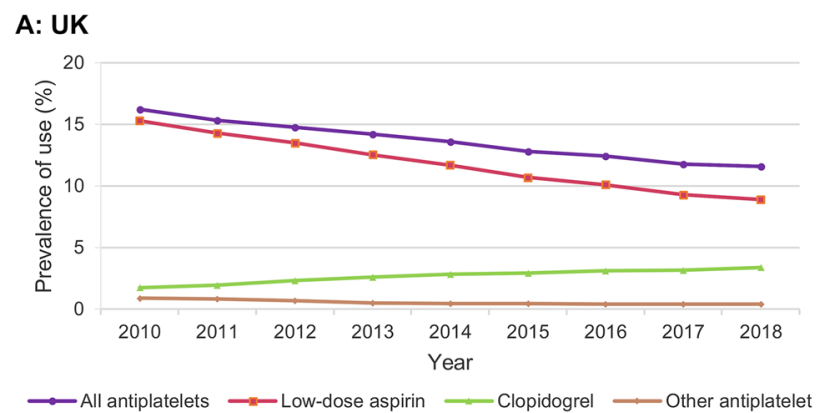

\section{C:Udine (Italy)}

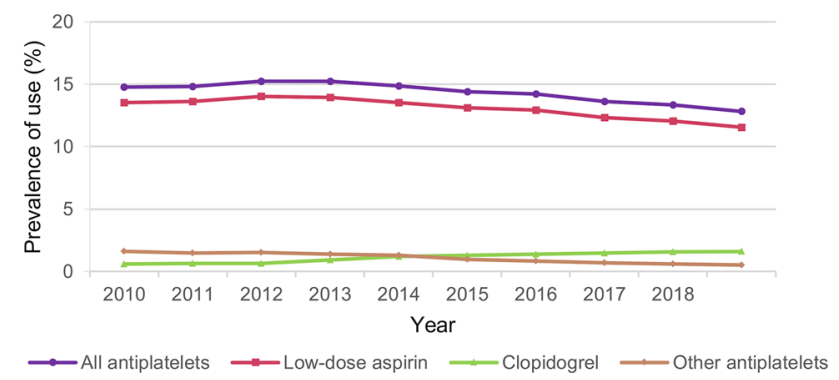

\section{Discussion}

In this population-based study across different European healthcare systems we observed a notable decline in the use of antithrombotics between 2010 and 2018 in all four

\section{B: RSD (Denmark)}

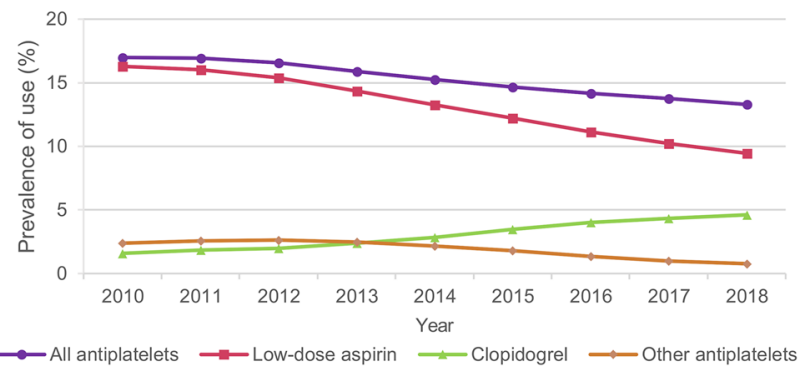

\section{D: Spain}

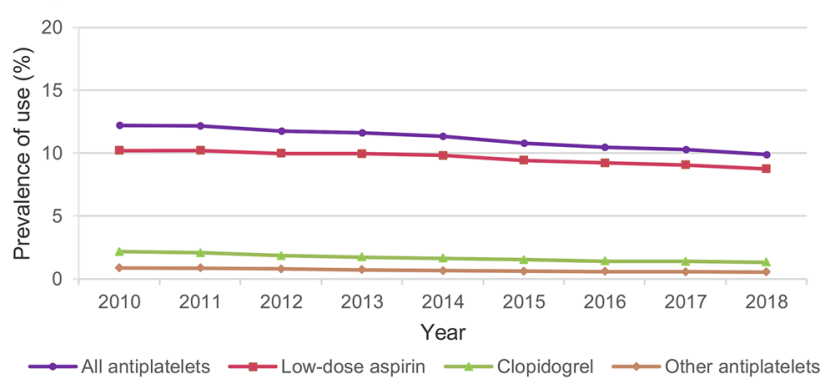

Fig. 4 Annual prevalence proportion of antiplatelets in A UK, B RSD (Denmark), C Udine (Italy), D Spain RSD, Region of Southern Denmark, UK, United Kingdom 
countries, and while a small steady increase in statin use was seen in the RSD, Udine and Spain, use of statins remained broadly consistent in the UK. The observed declines in antithrombotic use were driven by decreasing use of low-dose aspirin, and in the UK and RSD, this was clearly driven by a reduction in use among the elderly, suggesting possible patient/physician concerns about bleeding. Although each country saw a gradual steady increase in OAC use over the study period, this did not completely account for the level of decline in low-dose aspirin use; for example, absolute reductions in low-dose aspirin prevalence of $6.4 \%$ (UK) and 6.8\% (RSD) corresponded with increases of $1.8 \%$ (UK) and $2.5 \%$ (RSD) in OAC use.

We are aware of few other studies on this topic; however, two recent studies have similarly described a temporal trend of decreasing low-dose aspirin prevalence. In Wales, Protty et al. [11] found that low-dose aspirin prescription rates decreased by $15 \%$ from $2005-2016$. In a study based on US National Health Interview Survey data from the United States, self-reported aspirin use dropped from $32.6 \%$ in 2015 to $30.0 \%$ in 2012 , with a slighter larger drop seen for primary CVD prevention [12]. The decline in low-dose aspirin use for primary CVD prevention seen in our study for the UK and Spain, could be partly related to the 2009 publication of the Antithrombotic Trialists' Collaboration meta-analysis [13], which showed an uncertain absolute net value of lowdose aspirin in primary prevention due to higher bleeding risks [13]. Another possible explanation is the ESC's steadfast recommendation to avoid low-dose aspirin in individuals without prevalent CVD $[6,7,14]$, along with changes in the 2010 ESC guidelines relating to low-dose aspirin use in $\mathrm{AF}$ [3], as shown in previous studies [15, 16]. Although one could speculate that better control of CVD risk factors might explain declining low-dose aspirin use, further investigation would be needed in this area because reductions in some risk factors, such as hypertension and smoking, in high-income European countries have been accompanied by increases in others, for example, in diabetes and obesity [2]. The clear decline in low-dose aspirin use for secondary CVD prevention in the UK was not seen in Spain, which instead saw a reduction in clopidogrel use. In our analysis of UK secondary prevention data, the largest reduction in low-dose aspirin prescribing was to patients with stroke, with minor reductions to patients with other indications such as myocardial infarction. This reduction of low-dose aspirin use in stroke patients was partially compensated with an increase in clopidogrel and OAC use.

Statins are well-established as effective in the primary and secondary prevention of CVD [17-20], and have been consistently recommended in ESC guidelines for high-risk patients $[4,7]$. By 2018, prevalence of statin use was similar in the UK, RSD and Spain, being prescribed to between a fifth and a quarter of the population, compared with 1 in 7 individuals in Udine. The gradual small increase in statin use observed in the RSD, Udine and Spain, was not seen in the UK, albeit use remained the highest in the UK across study years. We are unaware of other studies describing contemporary trends in statin prescribing in Europe, with previous studies on the topic set in earlier time periods [21, 22]. The steady increases in OAC use for AF/VTE indications seen in our study have similarly been observed in other studies in Europe [15, 23, 24]. These increases were driven by a greater uptake of DOACs, in line with several previous reports from Europe [15, 16, 23-26] and America [27-29], indicating increasing confidence in the use of DOACs over VKAs. By 2018, levels of OAC use were broadly similar between countries in our study, ranging between $4.2 \%$ in Spain to $5.6 \%$ in the RSD. Although our study did not aim to compare drug use between individual countries, but rather describe trends within each country, it is still noteworthy to mention that several other factors, aside from guidelines and publication of pivotal studies may have impacted prescribing, for example, budgeting, reimbursement restrictions, introduction of generics, and different prescribing habits of physicians.

To our knowledge, our study, based on data from 2010-2018, is the first to make direct comparisons in the contemporary use of antithrombotics and statins between European countries with different healthcare structures. We used large population-based samples representative of the respective wider national/regional population, and applied age- and sex-standardisation to enable valid inter-country and inter-year comparisons, accounting for any effects from differences/changes in the demographic structures. It is important to note, however, that the findings from Italy may not be representative of regions outside Friuli Venezia Giulia, as indicated by a recent report from the Italian Medicines Agency that shows large inter-region variability in the use of some cardiovascular drugs [30]. Another small limitation is that drug use during hospitalisations will not have been captured in the databases; however, antithrombotics and statins are long-term therapies prescribed in primary care and therefore misclassification levels will have been minimal. Also, we did not have data to our disposal to evaluate primary/secondary CVD prevention in the RSD and Udine, and therefore were unable to evaluate whether they followed the respective prescribing trends seen in the UK or Spain.

In conclusion, antithrombotic use in the UK, RSD, Udine and Spain has declined between 2010 and 2018, driven by a reduction in use of low-dose aspirin that is not completely explained by a gradual increase in OAC use. This reduction in low-dose aspirin use was much more pronounced for patients without CVD, and because these patients accounted for the majority of patients analysed, the overall trend largely reflects the changes among the 
primary CVD prevention population. At the same time, use of statins has remained rather constant, increasing to a small extent in the RSD, Udine and Spain. Further studies of the prevalence of low-dose aspirin use for primary/ secondary CVD prevention would help explore this topic further. Analyses of the wider-scale uptake of lifestyle changes for CVD prevention, and scale of bleeding concerns around preventative aspirin use, may also help to understand our study's findings.

Supplementary Information The online version contains supplementary material available at https://doi.org/10.1007/s00228-021-03250-6.

Acknowledgements We thank Susan Bromley of EpiMed Communications Ltd, Abingdon, UK provided medical writing assistance funded by Bayer AG. We would also like to thank the excellent collaboration of primary care practitioners participating in BIFAP program (Spain). IQVIA provided the IMRD-UK incorporating data from THIN, a Cegedim Database. Reference made to THIN is intended to be descriptive of the data asset licensed by IQVIA.

Authors' contributions Study concept LAGR, DG, PV, MSG; study design LAGR, DG, LCS, PV; acquisition of the data: LAGR, DG, MG, FV, CC, SR; analysis of the data LAGR, DG, LCS, SR, FV; interpretation of the data: LAGR, DG, LCS, PV, FdA, JH; reviewing manuscript drafts all authors; approval of the final draft to be submitted for publication all authors.

Funding This work was supported by Bayer AG (CEIFE's contributions to the study only); grant number is not applicable.

Data availability Data are available from the corresponding author upon reasonable request.

Code availability Code is available from the corresponding author upon reasonable request.

\section{Declarations}

Ethics approval The UK study was approved by the Independent Scientific Research Committee for IMRD (reference number 19THIN077). Data collection for IMRD was approved by the South East Multicentre Research Ethics Committee in 2003 and individual studies using IMRD data do not require separate ethical approval if only anonymized data are used. The project was approved by the Region of Southern Denmark and is registered on the record of data processing activities in the region (j.nr.18/51966). Danish law does not require approval from an ethics board or informed consent for register studies. The Spanish part of the study was approved by the BIFAP Scientific Committee (reference number: 11/2019). Spanish law does not require ethical approval for epidemiological studies using fully anonymized data. For the Italian part of the study, approval from an ethics committee was not required because the databases used in the analyses - from the Regional Epidemiological Repository - are completely anonymous. As it was not possible to know the subjects' identities, informed consent was also not required.

Consent to participate Not applicable.

Consent for publication Not applicable.
Conflicts of interest LAGR works for CEIFE, which has received research funding Bayer AG. LAGR has also received honoraria for serving on advisory boards for Bayer AG. DG has received honoraria from AstraZeneca (Sweden) for participation as a coinvestigator on a research project outside the submitted work; and receiving speaker honorarium from Bristol-Myers Squibb outside the submitted work. FdA has received unrestricted research grants from Instituto de Salud Carlos III, Instituto Teófilo Hernando, Chiesi and Sanofi-Pasteur, for other research projects. JH has participated in research projects funded by Alcon, Almirall, Astellas, Astra-Zeneca, Boehringer-Ingelheim, Novo Nordisk, Servier and LEO Pharma, all with funds paid to the institution where he was employed (no personal fees) and with no relation to the current study. LCS, SR-M, MG, CC and FV declare no conflicts of interest. PV and MS-G are employees of Bayer AG.

Open Access This article is licensed under a Creative Commons Attribution 4.0 International License, which permits use, sharing, adaptation, distribution and reproduction in any medium or format, as long as you give appropriate credit to the original author(s) and the source, provide a link to the Creative Commons licence, and indicate if changes were made. The images or other third party material in this article are included in the article's Creative Commons licence, unless indicated otherwise in a credit line to the material. If material is not included in the article's Creative Commons licence and your intended use is not permitted by statutory regulation or exceeds the permitted use, you will need to obtain permission directly from the copyright holder. To view a copy of this licence, visit http://creativecommons.org/licenses/by/4.0/.

\section{References}

1. Townsend N, Wilson L, Bhatnagar P, Wickramasinghe K, Rayner M, Nichols M (2016) Cardiovascular disease in Europe: epidemiological update 2016. Eur Heart J 37(42):3232-3245. https://doi. org/10.1093/eurheartj/ehw334

2. Timmis A, Townsend N, Gale C, Grobbee R, Maniadakis N, Flather M et al (2017) European Society of Cardiology: Cardiovascular Disease Statistics 2017. Eur Heart J 39(7):508-579. https://doi.org/10.1093/eurheartj/ehx628

3. Camm AJ, Kirchhof P, Lip GYH, Schotten U, Savelieva I, Ernst S et al (2010) Guidelines for the management of atrial fibrillation: The Task Force for the Management of Atrial Fibrillation of the European Society of Cardiology (ESC). Eur Heart J 31(19):2369 2429. https://doi.org/10.1093/eurheartj/ehq278

4. Mach F, Baigent C, Catapano AL, Koskinas KC, Casula M, Badimon L et al (2020) 2019 ESC/EAS Guidelines for the management of dyslipidaemias: lipid modification to reduce cardiovascular risk. Eur Heart J 41(1):111-188. https://doi.org/10. 1093/eurheartj/ehz455

5. Roffi M, Patrono C, Collet JP, Mueller C, Valgimigli M, Andreotti $\mathrm{F}$ et al (2016) 2015 ESC Guidelines for the management of acute coronary syndromes in patients presenting without persistent ST-segment elevation: Task Force for the Management of Acute Coronary Syndromes in Patients Presenting without Persistent ST-Segment Elevation of the European Society of Cardiology (ESC). Eur Heart J 37(3):267-315. https://doi.org/ 10.1093/eurheartj/ehv320ehv320[pii]

6. Piepoli MF, Hoes AW, Agewall S, Albus C, Brotons C, Catapano AL et al (2016) 2016 European Guidelines on cardiovascular disease prevention in clinical practice: The Sixth Joint Task Force of the European Society of Cardiology and Other Societies on Cardiovascular Disease Prevention in Clinical Practice (constituted by 
representatives of 10 societies and by invited experts)Developed with the special contribution of the European Association for Cardiovascular Prevention \& Rehabilitation (EACPR). Eur Heart J 37(29):2315-2381. https://doi.org/10.1093/eurheartj/ehw106

7. Perk J, De Backer G, Gohlke H, Graham I, Reiner Ž, Verschuren $M$ et al (2012) European Guidelines on cardiovascular disease prevention in clinical practice (version 2012): The Fifth Joint Task Force of the European Society of Cardiology and Other Societies on Cardiovascular Disease Prevention in Clinical Practice (constituted by representatives of nine societies and by invited experts) Developed with the special contribution of the European Association for Cardiovascular Prevention \& Rehabilitation (EACPR)†. Eur Heart J 33(13):1635-1701. https://doi.org/10.1093/eurheartj/ ehs092

8. Halvorsen S, Andreotti F, ten Berg JM, Cattaneo M, Coccheri S, Marchioli R et al (2014) Aspirin therapy in primary cardiovascular disease prevention: a position paper of the European Society of Cardiology working group on thrombosis. J Am Coll Cardiol 64(3):319-327. https://doi.org/10.1016/j.jacc.2014.03.049S07351097(14)02579-0[pii]

9. De Caterina R, Aimo A, Ridker PM (2020) Aspirin Therapy for Primary Prevention: The Case for Continuing Prescribing to Patients at High Cardiovascular Risk-A Review. Thromb Haemost 120(2):199-206. https://doi.org/10.1055/s-0039-3400294

10. Eurostat. https://ec.europa.eu/eurostat/data/database. Accessed March 2020

11. Protty MB, Wilkins SJ, Hoskins HC, Dawood BB, Hayes J (2018) Prescribing patterns of oral antiplatelets in Wales: evolving trends from 2005 to 2016. Future Cardiol 14(4):277-282. https://doi.org/ $10.2217 / \mathrm{fca}-2018-0003$

12. Stuntz M, Bernstein B (2016) Recent trends in the prevalence of low-dose aspirin use for primary and secondary prevention of cardiovascular disease in the United States, 2012-2015. Prev Med Rep 5:183-186. https://doi.org/10.1016/j.pmedr.2016.12.023

13. Baigent C, Blackwell L, Collins R, Emberson J, Godwin J, Peto $R$ et al (2009) Aspirin in the primary and secondary prevention of vascular disease: collaborative meta-analysis of individual participant data from randomised trials. Lancet 373(9678):1849-1860. https://doi.org/10.1016/S0140-6736(09)60503-1S0140-6736(09) 60503-1[pii]

14. Kirchhof P, Benussi S, Kotecha D, Ahlsson A, Atar D, Casadei B et al (2016) 2016 ESC Guidelines for the management of atrial fibrillation developed in collaboration with EACTS. Europace 18(11):1609-1678. https://doi.org/10.1093/europace/euw295

15. Apenteng PN, Gao H, Hobbs FR, Fitzmaurice DA (2018) Temporal trends in antithrombotic treatment of real-world UK patients with newly diagnosed atrial fibrillation: findings from the GARFIELD-AF registry. BMJ Open 8(1):e018905. https://doi.org/10. 1136/bmjopen-2017-018905

16. Camm AJ, Accetta G, Ambrosio G, Atar D, Bassand J-P, Berge E et al (2017) Evolving antithrombotic treatment patterns for patients with newly diagnosed atrial fibrillation. Heart 103(4):307-314. https://doi.org/10.1136/heartjnl-2016-309832

17. Taylor F, Ward K, Moore TH, Burke M, Davey Smith G, Casas JP, et al (2011) Statins for the primary prevention of cardiovascular disease. Cochrane Database Syst Rev (1): Cd004816 DOI https:// doi.org/10.1002/14651858.CD004816.pub4
18. Brugts JJ, Yetgin T, Hoeks SE, Gotto AM, Shepherd J, Westendorp RG et al (2009) The benefits of statins in people without established cardiovascular disease but with cardiovascular risk factors: meta-analysis of randomised controlled trials. BMJ 338:b2376. https://doi.org/10.1136/bmj.b2376

19. Pignone M, Phillips C, Mulrow C (2000) Use of lipid lowering drugs for primary prevention of coronary heart disease: metaanalysis of randomised trials. BMJ 321(7267):983-986. https:// doi.org/10.1136/bmj.321.7267.983

20. Law MR, Wald NJ, Rudnicka AR (2003) Quantifying effect of statins on low density lipoprotein cholesterol, ischaemic heart disease, and stroke: systematic review and meta-analysis. BMJ 326(7404):1423. https://doi.org/10.1136/bmj.326.7404.1423

21. Vancheri F, Backlund L, Strender L-E, Godman B, Wettermark B (2016) Time trends in statin utilisation and coronary mortality in Western European countries. BMJ Open 6(3):e010500. https:// doi.org/10.1136/bmjopen-2015-010500

22. Walley T, Folino-Gallo P, Stephens P, Van Ganse E (2005) Trends in prescribing and utilization of statins and other lipid lowering drugs across Europe 1997-2003. Br J Clin Pharmacol 60(5):543551. https://doi.org/10.1111/j.1365-2125.2005.02478.x

23. Loo SY, Dell'Aniello S, Huiart L, Renoux C (2017) Trends in the prescription of novel oral anticoagulants in UK primary care. $\mathrm{Br}$ J Clin Pharmacol 83(9):2096-2106. https://doi.org/10.1111/bcp. 13299

24. Gadsbøll K, Staerk L, Fosbøl EL, Sindet-Pedersen C, Gundlund A, Lip GYH et al (2017) Increased use of oral anticoagulants in patients with atrial fibrillation: temporal trends from 2005 to 2015 in Denmark. Eur Heart J 38(12):899-906. https://doi.org/10.1093/ eurheartj/ehw658

25. Vinogradova Y, Coupland C, Hill T, Hippisley-Cox J (2018) Risks and benefits of direct oral anticoagulants versus warfarin in a real world setting: cohort study in primary care. BMJ 362:k2505. https://doi.org/10.1136/bmj.k2505

26. Maura G, Billionnet C, Drouin J, Weill A, Neumann A, Pariente A (2019) Oral anticoagulation therapy use in patients with atrial fibrillation after the introduction of non-vitamin $\mathrm{K}$ antagonist oral anticoagulants: findings from the French healthcare databases, 2011-2016. BMJ Open 9(4):e026645. https://doi.org/10.1136/ bmjopen-2018-026645

27. Lutsey PL, Walker RF, MacLehose RF, Alonso A, Adam TJ, Zakai NA (2019) Direct oral anticoagulants and warfarin for venous thromboembolism treatment: Trends from 2012 to 2017. Research and Practice in Thrombosis and Haemostasis 3(4):668-673. https://doi.org/10.1002/rth2.12222

28. Marzec LN, Wang J, Shah ND, Chan PS, Ting HH, Gosch KL et al (2017) Influence of Direct Oral Anticoagulants on Rates of Oral Anticoagulation for Atrial Fibrillation. J Am Coll Cardiol 69(20):2475-2484. https://doi.org/10.1016/j.jacc.2017.03.540

29. Machado-Alba JE, Gaviria-Mendoza A, Machado-Duque ME, Tovar-Yepes C, Ruigómez A, García Rodríguez LA (2021) Use of non-vitamin $\mathrm{K}$ antagonist oral anticoagulants in Colombia: A descriptive study using a national administrative healthcare database. Pharmacoepidemiol Drug Saf 30(4):426-434. https://doi. org/10.1002/pds.5124

30. Osservatorio Nazionale Sull 'Ompiego Dei Medicinali L'uso dei Farmaci in Italia Rapporto Nazionale Anno 2019. 